\title{
Habitat use by giant pandas Ailuropoda melanoleuca in the Wanglang Nature Reserve, Sichuan, China
}

\author{
Dong-Wei Kang ${ }^{1}$, Hong-Wei Yang ${ }^{1}$, Jun-Qing Li ${ }^{1 *}$, You-Ping Chen ${ }^{2}$ and Lian-Jun Zhao ${ }^{2}$
}

\begin{abstract}
Background: To better understand the ecological requirements of the giant panda Ailuropoda melanoleuca in the wild, field surveys were carried out at both the microhabitat scale and foraging site scale in Wanglang National Nature Reserve, Sichuan, China.

Results: The results indicated that (1) at the microhabitat scale, giant pandas usually occupied habitats with a high fallen-log density, lower shrub density, and bamboo coverage of 50\% to 75\%; (2) at the foraging site scale, pandas usually used sites with higher bamboo densities and taller and larger-diameter bamboo; and (3) giant pandas may abandon plots when the proportion of young bamboo decreases below average in the environment.
\end{abstract}

Conclusions: The availability of young bamboo is an important driving force in habitat selection by giant pandas, which could provide important reference for the conservation of giant pandas and their habitats.

Keywords: Foraging site; Giant panda; Habitat use; Microhabitat

\section{Background}

The giant panda Ailuropoda melanoleuca is a flagship species for efforts related to habitat conservation, is one of the most important rare and endangered species in the world, and is a category I protected species on the Red List of China (Wei et al. 2000). Despite efforts by the government, international organizations, and local people, loss and fragmentation of panda habitat threaten the species throughout its range (State Forestry Administration 2006; Shen et al. 2008). Thus, a deeper understanding of the habitat requirements of the giant panda is needed to develop specific conservation strategies for this endangered species.

A knowledge on the habitat requirements of animal species provides important information needed for conservation planning and policy making (Pan et al. 1998; Hu 2001; Ouyang et al. 2001; Wang et al. 2002; Liu et al. 2005, 2006; Yang et al. 2006; Xu et al. 2006; Swaisgood et al. 2010; Wang et al. 2010; Wei et al. 2011), but species-habitat relationships can vary among different

\footnotetext{
* Correspondence: lijunqing8100@gmail.com

${ }^{1}$ The Key Laboratory for Silviculture and Conservation of Ministry of Education, Beijing Forestry University, Beijing 100083, China Full list of author information is available at the end of the article
}

regions (Hu 2001; Wei et al. 2011; Panthi et al. 2012). For example, an abundance of research indicates that giant pandas usually use primary forests (Ran et al. 2003, 2004; Wang et al. 2006), although some research suggests that they also use secondary forests (Zhang et al. 2002a). Others reported that pandas use both primary and secondary forests equally with no significant habitat preference (Zeng et al. 2002; Zeng et al. 2003), so land managers should use caution if they wish to apply one region's conservation measures to another region (Wei et al. 2011). However, understanding the habitat requirements of an animal species in a specific area and then developing site-specific conservation strategies should be considered because this knowledge is important for managers who wish to implement effective conservation measures.

We report the results of field surveys on giant panda habitat in the Wanglang Nature Reserve. We identified variables related to giant panda habitat at the microhabitat scale and foraging site scale (Zhang et al. 2002b). The objective of our study was to discriminate habitat features which can be used to explain the habitat use of pandas in this area. By studying foraging sites used by giant pandas, we aimed to draw some general conclusions related to 
factors that drive habitat selection. These insights should deepen our understanding on the habitat requirements of giant pandas and facilitate identification of appropriate management strategies in this area.

\section{Methods}

\section{Study area}

Field work was conducted in the Wanglang National Nature Reserve (Figure 1), one of China's first nature reserves established to protect the giant panda in 1965, which is located in the northern part of Pingwu County $\left(103^{\circ} 50^{\prime}\right.$ to $104^{\circ} 58^{\prime} \mathrm{E}, 32^{\circ} 49^{\prime}$ to $\left.33^{\circ} 02^{\prime} \mathrm{N}\right)$ and is host to 27 pandas (State Forestry Administration 2006). The

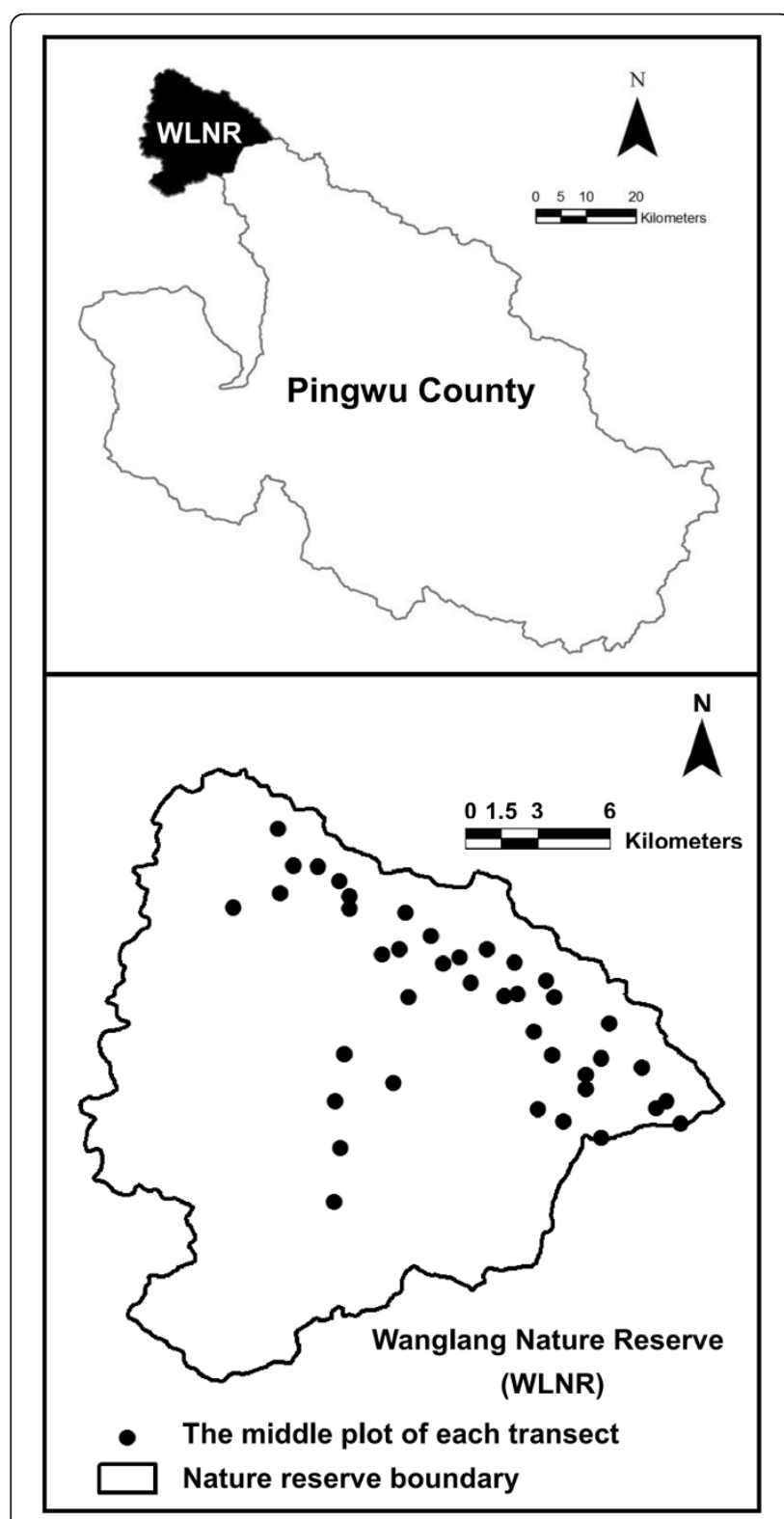

Figure 1 Vicinity map and map of the study area. reserve covers approximately $320 \mathrm{~km}^{2}$ with elevations ranging from 2,320 to $4,891 \mathrm{~m}$. The reserve receives $862.5 \mathrm{~mm}$ of rainfall annually, with the lowest mean air temperature of $-6.1^{\circ} \mathrm{C}$ in January and the highest at $12.7^{\circ} \mathrm{C}$ in July (Wang and Li 2008). Giant pandas in the reserve mainly feed on Fargesia denudate (Chen et al. 2003).

\section{Sampling method}

\section{Habitat use at the microhabitat scale}

In January, March, May, and June 2011, we conducted field surveys along 40 transects (Figure 1) in Wanglang Nature Reserve and repeated the surveys in April, May, July, and August 2012. All transects were established along an elevational gradient to ensure that each sampled transect contained typical and representative panda habitat. Each transect was at least $2 \mathrm{~km}$ long.

The location of panda-use plots along each transect was primarily determined by the presence of feces (Wei et al. 2000; Zhang et al. 2006, 2009). Habitat features were studied using $20 \times 20$-m sample plots. Panda signs more than $100 \mathrm{~m}$ apart from each other merited the establishment of different plots. In each $20 \times 20$-m plot centered on a feces location, two $2 \times 10-\mathrm{m}$ rectangular and perpendicular transects were established to investigate the densities of trees and shrubs (Wei et al. 2000; Zhang et al. 2006, 2009), with these rectangular plots placed so that their diagonals crossed at the feces location (Zhang et al. $2006,2009)$. Each side of a rectangular transect was parallel to the corresponding side of the $20 \times 20$-m square plot. Non-use plots were established every $100 \mathrm{~m}$ at different elevations along the transects to reflect the surrounding environment and also included the start and end plots at each end of the transect which were used as non-use plots (Zhang et al. 2011). Non-use plots were sampled in the same way as use plots. Table 1 describes the 13 microhabitat variables measured. In total, 515 plots were sampled for analysis (186 use plots and 329 non-use plots).

\section{Habitat use at the foraging site scale}

Five $1 \times 1$-m bamboo sites were established to investigate bamboo characteristics, such as bamboo density, basal diameter of old bamboo, height of old bamboo, young-bamboo density, and the proportion of young bamboo at each site (Table 1 ), and they were at the center of $20 \times 20-\mathrm{m}$ plots and the center of each $10 \times 10-\mathrm{m}$ plot in 2012 (Wei et al. 2000; Zhang et al. 2006, 2009). However, only four $1 \times 1-\mathrm{m}$ bamboo sites were randomly placed in each $10 \times 10-\mathrm{m}$ plot in 2011 , but we also used these data as a reference.

The bamboo sites surveyed in the panda-use plots were divided into two categories: forage and non-forage sites. A forage site was defined as a small area where remnants of bamboo foraged by giant pandas were found 
Table 1 Descriptions and definitions of variables used in this study

\begin{tabular}{|c|c|c|}
\hline Scale & Variable & Description \\
\hline \multirow[t]{13}{*}{ Microhabitat scale } & Slope aspect (deg) & $\begin{array}{l}\text { Nine categories: no aspect (slope of }<5^{\circ} \text { ), north, northeast, east, southeast, south, southwest, } \\
\text { west, and northwest }\end{array}$ \\
\hline & Slope (deg) & Five categories: $<10^{\circ}, 10^{\circ}$ to $20^{\circ}, 20^{\circ}$ to $30^{\circ}, 30^{\circ}$ to $40^{\circ}$, and $\geq 40^{\circ}$ \\
\hline & Canopy (\%) & $\begin{array}{l}\text { Canopy of overstory in sampling plot, four categories: }<25 \%, 25 \% \text { to } 50 \%, 50 \% \text { to } 75 \% \text {, } \\
\text { and } \geq 75 \%\end{array}$ \\
\hline & Shrub coverage (\%) & $\begin{array}{l}\text { Coverage of shrubs in the sampling plot, four categories: }<25 \%, 25 \% \text { to } 50 \%, 50 \% \text { to } 75 \% \text {, } \\
\text { and } \geq 75 \%\end{array}$ \\
\hline & Bamboo coverage (\%) & $\begin{array}{l}\text { Coverage of bamboo in the sampling plot, four categories: }<25 \%, 25 \% \text { to } 50 \%, 50 \% \text { to } 75 \% \text {, } \\
\text { and } \geq 75 \%\end{array}$ \\
\hline & Tree size $(\mathrm{cm})$ & $\begin{array}{l}\text { Average breast diameter (DBH) of trees in each } 100-\mathrm{m}^{2} \text { square plot nearest to the center of } \\
\text { a } 400-\mathrm{m}^{2} \text { plot }\end{array}$ \\
\hline & Tree dispersion (m) & Average distance of the nearest tree to the center in each $100-\mathrm{m}^{2}$ square plot \\
\hline & Tree density & Average number of trees in two $20-\mathrm{m}^{2}$ rectangular transects in a $400-\mathrm{m}^{2}$ plot \\
\hline & Shrub size $(\mathrm{cm})$ & Average DBH of shrubs in each $100-\mathrm{m}^{2}$ square plot nearest to the center of a $400-\mathrm{m}^{2}$ plot \\
\hline & Shrub dispersion (m) & Average distance of the nearest shrub to the center in each $100-\mathrm{m}^{2}$ square plot \\
\hline & Shrub density & Average number of shrubs in two $20-\mathrm{m}^{2}$ rectangular transects in a $400-\mathrm{m}^{2}$ plot \\
\hline & Fallen-log density & Total number of fallen logs ( $>10 \mathrm{~cm}$ in diameter) in a $400-\mathrm{m}^{2}$ plot \\
\hline & Tree stump density & Total number of tree stumps ( $>10 \mathrm{~cm}$ in diameter) in a $400-\mathrm{m}^{2}$ plot \\
\hline \multirow[t]{5}{*}{ Foraging site scale } & Bamboo density & Number of culms in a $1 \times 1-m$ bamboo site \\
\hline & Old-bamboo size (mm) & $\begin{array}{l}\text { Average basal diameter of culms in a } 1 \times 1 \text {-m bamboo site (five old bamboo culms were } \\
\text { measured randomly at each site) }\end{array}$ \\
\hline & Old-bamboo height (m) & $\begin{array}{l}\text { Average height of culms in a } 1 \times 1-m \text { bamboo site (five old bamboo culms were measured } \\
\text { randomly at each site) }\end{array}$ \\
\hline & Young-bamboo density & Number of young bamboo culms in a $1 \times 1$-m bamboo site \\
\hline & Young-bamboo proportion (\%) & Proportion of young bamboo culms in a $1 \times 1-\mathrm{m}$ bamboo site \\
\hline
\end{tabular}

(Zhang et al. 2009). Bamboo sites surveyed in the non-use plots were defined as control sites that reflected the surrounding environment. In total, 1,456 bamboo sites (151 forage sites, 413 non-forage sites, and 892 control sites) were sampled for analysis.

\section{Data analysis}

To describe habitat characteristics and compare habitat differences of panda-use and non-use plots, we used a $\chi^{2}$ test to compare discrete variables; for continuous variables, we used independent-sample $t$ tests when data were normally distributed and the Mann-Whitney $U$ test when the distributional assumptions were not met. To identify factors that differentiated microhabitat characteristics of panda-use and non-use plots, variables showing a significant difference between these two types of plots were subsequently analyzed with a logistic regression analysis. Also, to ensure that variables were independent, only variables with clear biological meaning were considered during subsequent analysis for those with absolute correlation coefficients of $>0.70$ (Schweiger et al. 2012).
To describe habitat characteristics of giant pandas at a foraging site scale, we used a one-way analysis of variance (ANOVA) test to compare means of variables among different bamboo site groups when data were normally distributed and a Kruskal-Wallis test when the distributional assumptions were not met. For those variables showing a significant difference, we then used a least significant difference (LSD) multiple comparison to test whether or not significant differences existed between all members when data were normally distributed and a Games-Howell multiple-comparison test when the distributional assumptions were not met. Furthermore, when the data type of the proportion of young bamboo was measured using percent, we used the Kruskal-Wallis test and Games-Howell multiple-comparison test to analyze such variables.

\section{Results}

Habitat use at the microhabitat scale

Seven (3 discrete and 4 continuous variables) of the 13 variables significantly differed between panda-use and non-use plots $(p<0.05)$ : slope aspect, shrub coverage, bamboo coverage, tree dispersion, shrub size, shrub 
Table $2 x^{2}$ test of discrete variables in panda-use and non-use plots

\begin{tabular}{|c|c|c|c|}
\hline \multirow[t]{2}{*}{ Variable } & \multirow[t]{2}{*}{ Habitat type } & \multicolumn{2}{|c|}{ Frequency (proportion) } \\
\hline & & $\begin{array}{l}\text { Use plots } \\
(n=186)\end{array}$ & $\begin{array}{c}\begin{array}{c}\text { Non-use plots } \\
(n=329)\end{array} \\
\end{array}$ \\
\hline \multirow[t]{10}{*}{ Slope aspect } & No aspect & $12(0.06)$ & $13(0.04)$ \\
\hline & North & $15(0.08)$ & $23(0.07)$ \\
\hline & Northeast & $15(0.08)$ & $23(0.07)$ \\
\hline & East & $29(0.16)$ & $50(0.15)$ \\
\hline & Southeast & $18(0.10)$ & $56(0.17)$ \\
\hline & South & $12(0.06)$ & $39(0.12)$ \\
\hline & Southwest & $29(0.16)$ & $52(0.16)$ \\
\hline & West & $15(0.08)$ & $45(0.04)$ \\
\hline & Northwest & $41(0.22)$ & $28(0.09)$ \\
\hline & \multicolumn{3}{|c|}{$x^{2}=29.33$, d.f. $=8, p=0.00$} \\
\hline \multirow[t]{6}{*}{ Slope } & $<10^{\circ}$ & $50(0.27)$ & $76(0.23)$ \\
\hline & $10^{\circ} \sim 20^{\circ}$ & $64(0.34)$ & $110(0.33)$ \\
\hline & $20^{\circ} \sim 30^{\circ}$ & $59(0.32)$ & $95(0.29)$ \\
\hline & $30^{\circ} \sim 40^{\circ}$ & $12(0.06)$ & $41(0.12)$ \\
\hline & $\geq 40^{\circ}$ & $1(0.01)$ & $7(0.02)$ \\
\hline & \multicolumn{3}{|c|}{$x^{2}=7.15$, d.f. $=4, p=0.13$} \\
\hline \multirow[t]{5}{*}{ Canopy } & $<25 \%$ & $34(0.18)$ & $79(0.24)$ \\
\hline & $25 \% \sim 50 \%$ & $81(0.44)$ & $118(0.36)$ \\
\hline & $50 \% \sim 75 \%$ & $59(0.32)$ & $111(0.34)$ \\
\hline & $\geq 75 \%$ & $12(0.06)$ & $21(0.06)$ \\
\hline & \multicolumn{3}{|c|}{$x^{2}=3.74$, d.f. $=3, p=0.29$} \\
\hline \multirow[t]{5}{*}{ Shrub coverage } & $<25 \%$ & $111(0.60)$ & $149(0.45)$ \\
\hline & $25 \% \sim 50 \%$ & $61(0.33)$ & $110(0.33)$ \\
\hline & $50 \% \sim 75 \%$ & $13(0.07)$ & $56(0.17)$ \\
\hline & $\geq 75 \%$ & $1(0.01)$ & $14(0.04)$ \\
\hline & \multicolumn{3}{|c|}{$x^{2}=19.45$, d.f. $=3, p=0.00$} \\
\hline \multirow[t]{5}{*}{ Bamboo coverage } & $<25 \%$ & $14(0.08)$ & $168(0.51)$ \\
\hline & $25 \% \sim 50 \%$ & $34(0.18)$ & $83(0.25)$ \\
\hline & $50 \% \sim 75 \%$ & $83(0.45)$ & $54(0.16)$ \\
\hline & $\geq 75 \%$ & $55(0.30)$ & $24(0.07)$ \\
\hline & \multicolumn{3}{|c|}{$x^{2}=140.24$, d.f. $=3, p=0.00$} \\
\hline
\end{tabular}

density, and fallen-log density (Tables 2 and 3). None of the correlation coefficients among these seven variables exceeded 0.70 , and thus, all of them were analyzed using a logistic regression analysis. Ultimately, bamboo coverage, shrub density, and fallen-log density were entered into the prediction equation, but only bamboo coverage and fallen-log density significantly contributed to the difference between use and non-use plots $\left(\chi^{2}=132.82\right.$, d.f. $=3, p<0.01$; Table 4$)$, with an overall correct prediction rate of $73.7 \%$. Giant pandas
Table 3 Mann-Whitney $U$ test of continuous variables in panda-use and non-use plots

\begin{tabular}{|c|c|c|c|c|}
\hline \multirow[t]{2}{*}{ Variable } & \multicolumn{2}{|c|}{ Mean (mean rank) } & \multirow{2}{*}{$\begin{array}{c}Z \\
\text { value }\end{array}$} & \multirow{2}{*}{$\begin{array}{c}p \\
\text { value }\end{array}$} \\
\hline & Use plots & Non-use plots & & \\
\hline Tree size & $\begin{array}{c}32.20(250.30) \\
\quad(n=180)\end{array}$ & $\begin{array}{c}29.07(233.80) \\
(n=299)\end{array}$ & -1.26 & 0.21 \\
\hline Tree dispersion & $\begin{array}{c}2.86(218.27) \\
(n=180)\end{array}$ & $\begin{array}{c}3.08(253.08) \\
(n=299)\end{array}$ & -2.67 & 0.01 \\
\hline Tree density & $\begin{array}{l}2.51(252.60) \\
\quad(n=186)\end{array}$ & $\begin{array}{l}2.55(261.05) \\
\quad(n=329)\end{array}$ & -0.62 & 0.53 \\
\hline Shrub size & $\begin{array}{c}2.41(280.19) \\
(n=184)\end{array}$ & $\begin{array}{c}2.03(243.21) \\
\quad(n=328)\end{array}$ & -2.71 & 0.01 \\
\hline Shrub dispersion & $\begin{array}{c}2.05(265.97) \\
(n=182)\end{array}$ & $\begin{array}{c}1.88(247.30) \\
(n=325)\end{array}$ & -1.38 & 0.17 \\
\hline Shrub density & $\begin{array}{l}4.74(212.09) \\
(n=186)\end{array}$ & $\begin{array}{l}7.24(283.96) \\
(n=329)\end{array}$ & -5.27 & 0.00 \\
\hline Fallen-log density & $\begin{array}{c}1.96(283.17) \\
(n=186)\end{array}$ & $\begin{array}{c}1.65(243.77) \\
(n=329)\end{array}$ & -2.99 & 0.00 \\
\hline Tree stump density & $\begin{array}{c}0.77(272.83) \\
(n=186)\end{array}$ & $\begin{array}{c}0.65(249.62) \\
(n=329)\end{array}$ & -1.95 & 0.05 \\
\hline
\end{tabular}

usually occupied habitats with a higher fallen-log density, a lower shrub density (Table 3), and bamboo coverage of $50 \%$ to $75 \%$ (Table 2 ).

\section{Habitat use at the foraging site scale}

Four of the five bamboo site variables significantly differed among the different bamboo site groups: bamboo density, old-bamboo size, old-bamboo height, and young-bamboo proportion $(p<0.05$, Table 5$)$. Multiple comparisons showed that the bamboo density, oldbamboo size, and old-bamboo height in forage sites were all significantly larger than those in both non-forage and control sites $(p<0.05$, Table 6$)$. Giant pandas usually used bamboo sites with a higher bamboo density, taller bamboo height, and larger bamboo diameter. However, proportions of young bamboo in forage and non-forage sites were all significantly lower than that in control sites $(p<0.05$, Table 6$)$, and no significant difference existed between forage and non-forage sites $(p>0.05$, Table 6$)$.

Table 4 Logistic regression analysis (backward stepwise (conditional) method) of seven microhabitat variables with significant differences

\begin{tabular}{lcccc}
\hline Variable & $\boldsymbol{B}$ & SE & Wald & Significance \\
\hline Bamboo coverage & 1.19 & 0.13 & 84.61 & 0.00 \\
Shrub density & -0.25 & 0.14 & 3.34 & 0.07 \\
Fallen-log density & 0.24 & 0.12 & 4.27 & 0.04 \\
Constant & -0.74 & 0.12 & 40.80 & 0.00 \\
\hline
\end{tabular}

$B$, regression coefficient; $\mathrm{SE}$, standard error. 
Table 5 ANOVA and Kruskal-Wallis test for foraging site variables among different bamboo site groups

\begin{tabular}{|c|c|c|c|c|c|}
\hline \multirow[t]{2}{*}{ Variable } & \multicolumn{3}{|c|}{ Mean (SD) or Mean (rank) } & \multirow[t]{2}{*}{$F$ or $X^{2}$} & \multirow[t]{2}{*}{$p$ value } \\
\hline & Forage sites $(n=151)$ & Non-forage sites $(n=413)$ & Control sites $(n=892)$ & & \\
\hline Bamboo density & $52.50(912.01)$ & $44.40(785.42)$ & $38.89(671.08)$ & 52.99 & 0.00 \\
\hline Old-bamboo size & $7.18(1.67)$ & $6.34(1.89)$ & $6.48(1.85)$ & 11.64 & 0.00 \\
\hline Old-bamboo height & $2.25(913.97)$ & $2.04(757.77)$ & $1.94(683.55)$ & 41.58 & 0.00 \\
\hline Young-bamboo density & $5.34(766.97)$ & $4.84(736.35)$ & $4.79(718.35)$ & 1.95 & 0.38 \\
\hline Young-bamboo proportion & 9.97 (643.16) & 10.77 (697.88) & 12.18 (757.12) & 12.56 & 0.00 \\
\hline
\end{tabular}

\section{Discussion}

\section{Microhabitat use}

Many factors affect habitat use by giant pandas, such as food distribution, concealment conditions, body size, and so on (Wei et al. 2000; Zhang et al. 2009). Of the 13 variables tested in this study, 7 significantly differed between panda-use and non-use plots (Table 2); however, only bamboo coverage, shrub density, and fallen-log density were entered into the prediction equation, indicating that they were the most important indicators of habitat use by giant pandas.

Giant pandas feed almost exclusively on bamboo ( $\mathrm{Hu}$ 2001; Yang et al. 2006; Zhang et al. 2009), so the life of giant pandas is directly influenced by the availability of bamboo. Habitat with lower bamboo coverage is not a suitable giant panda habitat because of the additional energy required for pandas to forage for food in such areas (Hu 2001). However, areas with high bamboo coverage impede the travel of pandas requiring the expenditure of additional energy (Hu 2001). Thus, habitat with medium levels of bamboo coverage provides adequate food for giant pandas and also allows pandas to more easily move across the landscape.

Fallen logs usually serve as passageways connecting different habitat areas and allow pandas to travel more easily within their habitat. Additionally, an abundance of fallen wood is an important characteristic of old-growth forests; based on this study, giant pandas typically occupy habitats with high fallen-log densities, which is consistent with previous reports stating that giant pandas require old-growth forest habitats (Zhang et al. 2011). Furthermore, shrubs are not a food of giant panda, and habitats with lower shrub densities could reduce the energy expenditure of giant panda when moving about (Wei et al. 2000).

\section{Foraging site use}

A panda can eat $10 \sim 18 \mathrm{~kg}$ of fresh leaves or stems or about $40 \mathrm{~kg}$ of new shoots per day and will spend more than $50 \%$ of the day foraging ( $\mathrm{Hu} \mathrm{2001;} \mathrm{Zhang} \mathrm{et} \mathrm{al.}$ 2009), so pandas need to conserve energy and search for high-quality food. Bamboo sites with a high density of bamboo, tall bamboo, and large-diameter bamboo stems provide high levels of biomass and high-quality and adequate food resources for giant pandas; this allows pandas to maximize their energy and nutrient intake in this type of foraging site and helps them reduce energy expenditures when moving in search of food (Zhang et al. 2009).

Giant pandas primarily feed on young bamboo shoots (Hu 2001; Zhang et al. 2009), and young bamboo provides high-quality food for giant pandas. This research confirms that proportions of young bamboo at both forage and non-forage sites were all significantly lower than that at control sites. Furthermore, no significant difference was found between forage and non-forage sites, which indicates that giant pandas would need to leave their current use plots when the proportion of young bamboo falls below average in the environment and search for sites with higher-quality food.

\section{Conclusions}

In conclusion, the availability of young bamboo is an important driving force in habitat selection by giant pandas.

Table 6 Multiple comparisons of four foraging site variables with significant differences

\begin{tabular}{|c|c|c|c|c|}
\hline Variable & Category & $\begin{array}{c}\text { Mean } \\
\text { difference }\end{array}$ & Significance & $\begin{array}{c}95 \% \\
\text { Confidence } \\
\text { interval }\end{array}$ \\
\hline \multirow[t]{3}{*}{ Bamboo density } & $\mathrm{F}-\mathrm{C}$ & 13.62 & 0.00 & $(7.82,19.41)$ \\
\hline & $\mathrm{N}-\mathrm{C}$ & 5.51 & 0.00 & $(2.10,8.92)$ \\
\hline & $\mathrm{F}-\mathrm{N}$ & 8.11 & 0.01 & $(1.96,14.25)$ \\
\hline \multirow[t]{3}{*}{ Old-bamboo size } & $\mathrm{F}-\mathrm{C}$ & 0.70 & 0.00 & $(0.38,1.02)$ \\
\hline & $\mathrm{N}-\mathrm{C}$ & -0.13 & 0.22 & $(-0.35,0.08)$ \\
\hline & $\mathrm{F}-\mathrm{N}$ & 0.83 & 0.00 & $(0.49,1.18)$ \\
\hline \multirow{3}{*}{$\begin{array}{l}\text { Old-bamboo } \\
\text { height }\end{array}$} & $\mathrm{F}-\mathrm{C}$ & 0.31 & 0.00 & $(0.19,0.43)$ \\
\hline & $\mathrm{N}-\mathrm{C}$ & 0.10 & 0.02 & $(0.01,0.19)$ \\
\hline & $\mathrm{F}-\mathrm{N}$ & 0.21 & 0.00 & $(0.08,0.34)$ \\
\hline \multirow{3}{*}{$\begin{array}{l}\text { Young-bamboo } \\
\text { proportion }\end{array}$} & $\mathrm{F}-\mathrm{C}$ & -2.21 & 0.01 & $(-4.03,-0.39)$ \\
\hline & $\mathrm{N}-\mathrm{C}$ & -1.41 & 0.02 & $(-2.63,-0.20)$ \\
\hline & $\mathrm{F}-\mathrm{N}$ & -0.80 & 0.59 & $(-2.72,1.12)$ \\
\hline
\end{tabular}

F-C, forage-control sites; N-C, non-forage-control sites; F-N, forage-non-forage sites. 


\section{Competing interests}

The authors declare that they have no competing interests.

\section{Authors' contributions}

DWK designed the study, performed the experiments and the statistical analysis, and drafted the manuscript. HWY participated in the performance of the experiments. JQL conceived of the study and participated in the design of the study. YPC and LJZ participated in the design of the study. All authors read and approved the final manuscript.

\section{Acknowledgements}

This study was supported by the National Key Technology Research and Development Program in the 11th Five-Year Plan of China (2008BADB0B04) and the National Natural Science Foundation of China (31170500). We would like to thank Xiaorong Wang, Zhiwei Yuan, Chunping Luo, Chunping Liang, Yong Zheng, Jie Ouyang, Jixu Zhao, Gaoshan Lan, Hualong Zhou, Xiaorong Xie, Yunxi Li, Xiong Gao, Wenlong Jiang, Yubo Zhang, and Lijuan Duan for participating in the fieldwork.

\section{Author details}

${ }^{1}$ The Key Laboratory for Silviculture and Conservation of Ministry of Education, Beijing Forestry University, Beijing 100083, China. ${ }^{2}$ Wanglang National Nature Reserve Administration Bureau, Sichuan 622550, China.

\section{Received: 28 September 2012 Accepted: 10 May 2013}

Published: 30 September 2013

\section{References}

Chen YP, Jiang SW, Zhao L, Huang JZ (2003) Surveillance on giant panda habitats in Wanglang Nature Reserve, Sichuan. Sichuan J Zool 22:49-50 (in Chinese with English summary)

Hu JC (2001) Research on the giant pandas. Shanghai Scientific and Technological Press, Shanghai (in Chinese)

Liu XH, Toxopeus AG, Skidmore AK, Shao XM, Dang GD, Wang TJ, Prins HHT (2005) Giant panda habitat selection in Foping Nature Reserve, China. J Wildl Manage 69:1623-1632

Liu XH, Skidmore AK, Bronsveld MC (2006) Assessment of giant panda habitat based on integration of expert system and neural network. Chin J Appl Ecol 17:438-443 (in Chinese with English summary)

Ouyang ZY, Liu JG, Xiao H, Tan YC, Zhang HM (2001) An assessment of giant panda habitat in Wolong Nature Reserve. Acta Ecol Sin 21:1869-1874 (in Chinese with English summary)

Pan WS, Gao ZS, Lü Z (1998) The natural refuge for giant pandas in Qinling. Peking University Press, Beijing (in Chinese)

Panthi S, Aryal A, Raubenheimer D, Lord J, Adhikari B (2012) Summer diet and distribution of the red panda (Ailurus fulgens fulgens) in Dhorpatan Hunting Reserve, Nepal. Zool Stud 51:701-709

Ran JH, Liu SY, Wang HJ, Sun ZY, Zeng ZY, Liu SC (2003) Effect of grazing on giant pandas' habitat in Yele Nature Reserve. Acta Theriol Sin 23:288-294 (in Chinese with English summary)

Ran JH, Zeng ZY, Wang H, Liu SY, Wang HJ, Liu SC (2004) A comparative study on habitat preference of giant pandas in primary and secondary forests. J Beijing For Univ 26:8-14 (in Chinese with English summary)

Schweiger AK, Ursula NM, Margit Z (2012) Small-scale habitat use of black grouse (Tetrao tetrix L.) and Rock Ptarmigan (Lagopus muta helvetica Thienemann) in the Austrian Alps. Eur J Wildl Res 58:35-45

Shen GZ, Feng CY, Xie ZQ, Ouyang ZY, Li JQ, Pascal M (2008) Proposed conservation landscape for giant pandas in the Minshan Mountains, China. Conserv Biol 22:1144-1153

State Forestry Administration (2006) The third national survey report on giant panda in China. Science Press, Beijing (in Chinese)

Swaisgood RR, Wei FW, Wildt DE, Kouba AJ, Zhang ZJ (2010) Giant panda conservation science: how far we have come. Biol Lett 6:143-145

Wang MJ, Li JQ (2008) Research on habitat restoration of giant panda after a grave disturbance of earthquake in Wanglang Nature Reserve, Sichuan Province. Acta Ecol Sin 28:5848-5855 (in Chinese with English summary)

Wang H, Li SG, Pan WS (2002) Population viability analysis of giant panda (Ailuropoda melanoleuca) in Qinling Mountains. Acta Sci Nat Univ Peking 38:756-761 (in Chinese with English summary)
Wang JH, Huang HL, Teng JR, Yang WY, Ma T (2006) Habitat selection by giant pandas in west of Baishuijiang Nature Reserve. Sichuan J Zool 25:771-775 (in Chinese with English summary)

Wang TJ, Ye XP, Skidmore AK, Toxopeus AG (2010) Characterizing the spatial distribution of giant pandas (Ailuropoda melanoleuca) in fragmented forest landscapes. J Biogeogr 37:865-878

Wei FW, Wang ZW, Hu JC (2000) Habitat use and separation between the giant panda and the red panda. J Mammal 81:448-455

Wei FW, Zhang ZJ, Hu JC (2011) Research advances and perspectives on the ecology of wild giant panda. Acta Theriol Sin 31:412-421 (in Chinese with English summary)

Xu WH, Ouyang ZY, Jiang ZY, Zheng H, Liu JG (2006) Assessment of giant panda habitat in the Daxiangling Mountain Range, Sichuan, China. Biodivers Sci 14:223-231 (in Chinese with English summary)

Yang CH, Zhang HM, Zhou XP, Wang PY, Wang XM (2006) Review of habitat selection in the giant panda (Ailuropoda melanoleuca). Acta Ecol Sin 26:3442-3453 (in Chinese with English summary)

Zeng ZY, Yue BS, Ran JH, Liu SY, Chen YP, Jiang SW (2002) Panda's exploitation of habitats at Wanglang Nature Reserve. J Sichuan Univ (Nat Sci) 39:1140-1144 (in Chinese with English summary)

Zeng T, Ran JH, Liu SY, Sun ZY, Liu SC, Zeng ZY (2003) Habitat exploitation by panda in the Baihe Nature Reserve. Chin J Appl Environ Biol 9:405-408 (in Chinese with English summary)

Zhang ZJ, Hu JC, Wu H (2002a) Comparison of habitat selection of giant pandas and red pandas in the Qionglai Mountains. Acta Theriol Sin 22:161-168 (in Chinese with English summary)

Zhang ZJ, Wei FW, Hu JC (2002b) Habitat selection and separation: a case for the giant panda and the red panda. J China West Normal Univ (Nat Sci) 28:111-116 (in Chinese with English summary)

Zhang ZJ, Wei FW, Li M, Hu JC (2006) Winter microhabitat separation between giant and red pandas in Bashania faberi bamboo forest in Fengtongzhai Nature Reserve. J Wild Manage 70:231-235

Zhang ZJ, Zhan XJ, Yan L, Li M, Hu JC, Wei FW (2009) What determines selection and abandonment of a foraging patch by wild giant pandas (Ailuropoda melanoleuca) in winter? Environ Sci Pollut Res 16:79-84

Zhang ZJ, Swaisgood RR, Zhang SN, Nordstrom LA, Wang HJ, Gu XD, Hu JC, Wei FW (2011) Old-growth forest is what giant pandas really need. Biol Lett 7:403-406

doi:10.1186/1810-522X-52-23

Cite this article as: Kang et al: Habitat use by giant pandas Ailuropoda melanoleuca in the Wanglang Nature Reserve, Sichuan, China. Zoological Studies 2013 52:23.

\section{Submit your manuscript to a SpringerOpen ${ }^{\odot}$ journal and benefit from:}

- Convenient online submission

- Rigorous peer review

- Immediate publication on acceptance

- Open access: articles freely available online

- High visibility within the field

- Retaining the copyright to your article

Submit your next manuscript at springeropen.com 